\title{
Research on Construct Sharing Platform of Large-Scale Instruments and Equipment in the Laboratory
}

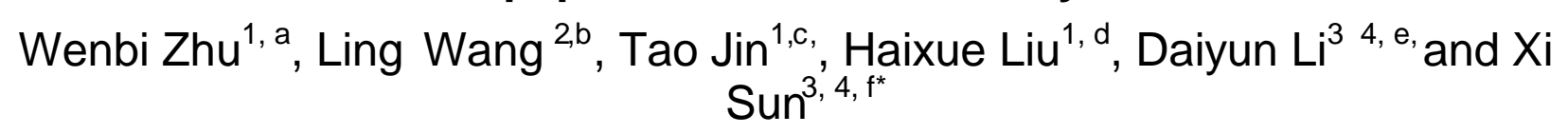

${ }^{1}$ Office of Educational Administration Tianjin Agricultural University Tianjin 300384, China

${ }^{2}$ Students' Affairs Division Tianjin Agricultural University Tianjin 300384, China

${ }^{3}$ College of Biological Engineering Tianjin Agricultural University Tianjin 300384, China

${ }^{4}$ Tianjin Engineering Research Center of Agricultural Products Processing Tianjin 300384, China

a zhuwenbi@tjau.edu.cn, b1397854344@qq.com, '625174343@qq.com, d514887257@qq.com, e345419731@qq.com, 'sunxiaoxisunxiao@163.com

*The corresponding author

Keywords: Large-scale; Instruments and equipment; Opening sharing platform; Networked

\begin{abstract}
For increase the use ratio of large-scale instruments and equipment in the university laboratory, establish the opening sharing management platform and realize the normalized and networked management, profound research on the management approaches of large-scale laboratory instruments and equipment combined with actual situation of Tianjin Agricultural University are carried out for the promotion of university education and scientific research orderly developing.
\end{abstract}

\section{Introduction}

With the improvement of China's scientific and technological development, and the enhancement economic level, the national investment for teaching and scientific research in colleges and universities also increased year by year, especially during the period of "11th five-year plan", "twelfth five-year" comprehensive investment construction, various universities have bought a lot of large instruments and equipment. How to carry out the scientific and standardized management for these expensive equipment to achieve maximum benefits, better for personnel training, scientific research and social services, is a large problem to be solved of instrument equipment management [1].

At present, Tianjin Agricultural University, with above 224 sets of large instruments and equipment, every one of them worth more than 100000 yuan, the total value is about 55.45 million yuan, the school leaders and teachers in the same way of the whole cooperation, after recent years of laboratory research and exploration for the management of large instruments and equipment daily, summarized some experience for your reference.

\section{Establish and Improve the Use of Large Equipment Regulations}

With the continuous development of the school education, the number of large instruments and equipment increased rapidly in recent years in our school. In order to further strengthen and improve the large instruments and equipment management, promote the use of large-scale instruments and equipment opening to the outside world, give full play to its investment efficiency, reduce duplication of purchase, improve efficiency, realize the resource sharing [2], hereby formulated "the measures for the management of large instruments and equipment open sharing", method specified that in the school of large instruments and equipment must be open to the entire school teachers and students, the school each year set up a special fund for large instrument open fund and maintenance funds, guarantee the large equipment daily operation. The main contents are as follows: 
(1) Schools put the experimental teaching center as units to establish an open platform of sharing the large instruments and equipment, publish the main information of our school open sharing service scope of all instruments and equipment, for internal and external inspection.

(2) The experimental teaching centers which have large instrument should publish the open time of large instruments and equipment timely, and updated at any time according to the booking situation.

(3) Instrument equipment management departments have specific equipment open management personnel and have high level of full-time professional and technical personnel responsible for maintenance and operation, to guarantee equipment performance as well.

(4) Users shall comply with the rules of operating the equipment and the related regulations, obey the management and guidance of operators, and pay attention to maintenance of laboratory environmental sanitation and order.

(5) After use the equipment, user and management personnel should fill in the "large instruments and equipment maintenance records" and relevant records, clear the used items timely.

\section{Establish the Large Equipment Sharing Platform, Achieve the Online Booking}

As school was stand-alone version of the management system in the past, cannot achieve the real-time, dynamic scientific management [3-5], people who need to use large instruments and equipment don't know where the instrument is and what time they can use, generally they need to ask around before use, it invisible wasted precious time from teachers, some even directly go to the examination center to external test with a high price, and schools' large equipment are idle for a long time. In order to ensure that the school teaching and scientific research going orderly, since September 1, 2013, through establish the open sharing platform of large instruments in our school, realize the user online query, online booking. Users by entering a keyword to query the relevant information of large instruments and equipment to be used (such as instrument name, location, and contact method, main accessories and configuration, main technical index, the main function, application scope, available open time, etc.), be clear at a glance. Administrators can real-time check the large investment booking details of users, and completes the review reply in time. Online booking platform greatly save the time, the teachers also can guarantee the standard and efficient operation of the large instruments and equipment. The Shared platform since running praised by the great majority of teachers and students, our school management level of large instruments and equipment has been improved significantly.

\section{Establish Large Instruments and Equipment Standard Operating Procedures}

Large instruments and equipment due to its high value, complex structure, in use process, generally more operation steps, and the matters of attention in the use process are also more, a little careless action is likely to cause equipment damage, and even personal injury [6], so that the use of large-scale instruments and equipment must be operated in accordance with the standard operating procedures. While, many large instrument is generally only use manual, do not have standard operating procedures, even a lot of equipment are imported, have English manual, professional management personnel of large instruments in our school, through collect information, trial and error, serious sums up a set of standard operating procedures for the entire school teachers and students to reference. By reference to standard operating procedures, not only greatly save the time of teachers and students to master the use of large-scale instruments and equipment, but also avoided the phenomenon which caused by not dare to use because of ignorant or use carelessly [7], ensure them can do research safely, also to ensure the integrity rate of the large instruments and equipment.

\section{Establish Large Instrument and Equipment "Scientific Management" Mechanism}

Because of the large instruments and equipment is expensive, complex structure, in order to 
guarantee the normal operation of the large-scale instrument and timely maintenance, the school through the introduction of professional technical personnel to improve experiment team structure, through professional training to improve the quality of the equipment management personnel and their business level, set up effective mechanism of incentive and constraint to force experiment technicians to manage and use well of large instruments and equipment [8-9]. If other people want to use this instrument must get the management personnel's agree, after management training guide, in strict accordance with standard operating procedures, obey management personnel management before use. After use the equipment, user and management personnel should fill in the "large instruments and equipment maintenance records", and clear the used items timely. If in use process found instrument failure, user need to promptly eliminate the trouble, ensure the normal operation of the instrument. Establishment of large-scale instruments and equipment effectiveness evaluation and assessment system at the same time, the money used is connected with the existing large apparatus and management performance. Then large instruments and equipment with low openness and low year-end assessment, school can move it to the departments which need to use it more.

\section{Establishment of Large-Scale Instruments Open Sharing Fund}

The school each year set up a special fund for large instrument open fund and maintenance funds, special funds in the form of the project sponsor. People, such as our school teacher who undertake teaching and scientific research project, scientific research personnel, experimental technical personnel, all of them can apply the large investment open fund to the experimental teaching center according to the needs of work. Funds used to ensure the need of teaching and longitudinal research projects first, especially in basic research and the needs of the development of emerging and interdisciplinary subject, appropriate to consider the requirements of the horizontal scientific research project [10]. Senior undergraduate and graduate thesis and practice topic project can give the application through their instructor. The fund is mainly used for large equipment operation consumable material cost and large equipment daily maintenance, etc. To apply for the user to fill in the "large instruments and equipment using open sharing application form", can be used upon approval by the experimental teaching center. Fund winner at the end of each year need to submit the fund usage reports to the experiment teaching center which the used instruments belongs to, school according to the actual open situation of the experiment teaching center to organize the equipment's annual review and assessment, commend and reward the departments and individuals which make excellent grades in the work of make open use of instrument. Fund appraisal methods mainly depend on whether the applicant has obtained a patent for invention, or published different levels research papers, etc.

\section{Conclusion}

The use and management of large precise instrument is an important and difficult work, therefore, we should ponder earnestly from the management system and operational mechanism, actively explore the innovation of large instruments and equipment resources management system and operational mechanism, fully mobilize all aspects of the positive factors, through the establishment of assessment and incentive system, the construction of open sharing mechanism, independent training equipment operators, strengthening inspection supervision and implementation to be repaid and other measures, to promote the efficient use of large equipment, better serve teaching, scientific research and social services.

\section{References}

[1] LIN Feng-ping, HUANG Fei, TANG Liang-hua, et al. Exploration of the Construction of Large-scale Instruments and Equipment Open-sharing Platform in University [J]. Experiment Science and Technology, 2012, 10(5):180-182.

[2] Liu Xiao-mei, Jiang li, Zuang Xian-ji. Research on opening and sharing of experimental 
equipment in universities [J]. Science \& Technology Information, 2012(8):8-9.

[3] LIU Li-qin, CHEN Yong-qing. Research and practice on sharing of valuable large instruments in colleges and universities [J]. Experimental Technology and Management, 2011, 28(2):208-210.

[4] QI Xue-mei, LIU Hong-chang. Thinking of Reform of Management and Utilization Methods of the Large Scale Analytical Apparatus [J]. Experimental Technology and Management, 2010, 27(11):228-231.

[5] CAI Bing, LIU Shu-ling, YIN Ling-na, et al. Exploration and Practice on the Opening-Up and Sharing of Large-Scale Apparatus and Equipment in Universities[J]. Research and Exploration in Laboratory, 2014, 33(2):259-263.

[6] CHEN Xiao-ling, GAO Zhou-quan. Improving the Investment Benefit of Large-Scales [J]. Instrument and Equipment in Universitie, 2014, 33(1):267-270.

[7] CHEN Hong, LU Juan-juan, XU Xi-rong. Discussion on Integrative Information Management of Large-Scale Instruments [J]. Experimental Technology and Management, 2012, 29(7):212-214.

[8] YANG Shu-guo, HUANG Le, WU Xiao-feng, et al. Strengthening Evaluation to Increase the Utilization Efficiency of Large-scale Equipment in Higher Education Institutions [J]. Research and Exploration in Laboratory, 2012, 31(8):179-182.

[9] BI Wei-min, FANG Kun. Practice and Exploration of Efficiency Evaluation of Large-Scale Instruments in Universities [J]. Research and Exploration in Laboratory, 2011, 30(9):410-413.

[10]LIN Hai-dan, WU Li-qun, FAN Bing. Laboratory Team Construction Mechanisms in Colleges and Universities [J]. Research and Exploration in Laboratory, 2012, 31(2):173-174. 